\title{
A Relação Universidade-Empresa no Brasil e $\circ$ "Argumento da Hélice Tripla" *
}

\author{
Renato Dagnino \\ Instituto de Geociências /Departamento de Política de Ciência e Tecnologia / UNICAMP)
}

RESUMO

A relação universidade-empresa (relação U-E) é abordada tendo como guia o "argumento da Hélice Tripla" (argumento HT), entendido como combinação de duas correntes de pensamento elaboradas nos países avançados - a "Segunda Revolução Acadêmica" e a que ressalta a importância das relaçôes com o entorno na competitividade das empresas - e de uma proposição de Política Científica e Tecnológica (PCT) — os Pólos e Parques Tecnológicos — delas decorrente.

Analisando a evolução das interpretações sobre a relação U-E na América Latina - os marcos de referência utilizados, as posturas analíticas ou disciplinares, sua influência junto à comunidade de pesquisa e na elaboração de PCT mostra-se como o argumento HT contribuiu para que a interpretação que até o final dos anos 1980 era dominante perdesse influência e como o debate em curso entre essas duas atuais posições parece encaminhar-se.

\footnotetext{
O autor agradece ao CNPq o apoio à realização da pesquisa que originou este trabalho. Agradece, também, aos colegas e alunos do DPCT que criticaram sua primeira versão, especialmente ao prof. Erasmo Gomes, que para ela contribuiu decisivamente. Finalmente, agradece a atenta crítica e às sugestões de modificações feitas pelos pareceristas anônimos da RBI.
} 
Por oferecer um padrão para análise crítica das mudanças nos modelos explicativo e normativo-institucional da PCT em países avançados e periféricos, o argumento HT pode informar novas interpretações, mais aderentes ao cenário de democratização ora em construção no País.

Palavras-Chave | Política Científica e Tecnológica; Relação Universidade-Empresa; Argumento da Hélice Tripla; Pólos e Parques Tecnológicos; América Latina

Código JEL | O38

\section{ABSTRACT}

The university-firm relationship (UFR) is approached having as a guide the "Triple Helix statement" (TH), undestood as a combination of two currents of thought produced in advanced countries - the "Second Academic Revolution" and the one that stresses the relations between firms and their context as competitiveness factors - and an associated measure of Science and Technology Policy (STP) - the Technological Parks.

Analysing the evolution of UFR interpretations in Latin America - the frameworks used, the analytic or disciplinary postures, their influence on the research community and in the STP - the paper shows how TH debilitated the interpretation that had been dominant until the end of the 1980s, and how the debate in course between these two present positions tends to progress.

By offering a standard for critical analysis of the changes in the explanatory and normative-institutional models of STP in advanced and peripheric countries, $\mathrm{TH}$ can inform new interpretations more adherent to the democratization scenario that is being constructed in the country.

KeYWORDS I Science and Technology Policy; University-firm Relationship; Triple Helix Statement; Technological Parks; Latin America

JEL CoDE $\mid$ O38 


\section{Introdução}

Este trabalho aborda o tema da relação universidade-empresa (U-E), e dos instrumentos que visam a estimulá-la para alcançar o resultado positivo predicado pela política de inovação em curso no País. Sua intenção é complementar estudos já realizados sobre essa relação, ou mais precisamente sobre a evolução da sua interpretação pelos pesquisadores do tema. Isto é feito através da apreciação dos marcos de referência utilizados, das posturas analíticas (ou, em certa medida, disciplinares) e de seus desdobramentos no plano da Política Científica e Tecnológica (PCT). Sua abordagem é, em conseqüência, às vezes temática, outras vezes histórica; às vezes focada no ambiente internacional, outras vezes na América Latina.

O trabalho tem como guia a discussão da hipótese de que estaria ocorrendo um crescente virtuosismo na relação U-E. Denominada como "argumento da Hélice Tripla” (argumento HT), ela é apresentada como o resultado da combinação de duas correntes de pensamento relacionadas ao tema, e da proposição de um instrumento específico de promoção dessa relação, delas derivada.

O trabalho se inicia com a crítica da produção acadêmica dos países avançados alinhada com o argumento HT, onde ele foi formulado e tem alcançado crescente influência no ambiente dos estudiosos do tema, da comunidade de pesquisa, que desenvolve suas atividades em universidades e em organizaçóes públicas e privadas, e na elaboração da PCT. O fato de que, como é usual, estudiosos brasileiros tenham internalizado o instrumental analítico dessa produção acadêmica, e também algumas das avaliaçôes acerca do comportamento dos atores envolvidos e das tendências esperadas que ela tem difundido, levou a uma análise similar sobre a sua produção acadêmica. Ela se justifica entre outras razões, pela intenção academicamente legítima de relacionar a produção acadêmica nacional com as tendências internacionais mais importantes.

A adoção do argumento HT como um guia ou referência deste trabalho não se deve somente ao fato dele ter desempenhado aqui um papel semelhante. Ele parece ter atuado aqui como um argumento de autoridade que reforçou uma das posturas analíticas que, embora não se tenham ainda abertamente confrontado, há muito se expressam no cenário nacional. Adicionalmente, devido à percepção de que ele contribuiu para desencadear a mudança em curso no 
modelo explicativo e, em conseqüência, no modelo normativo-institucional da PCT brasileira, dando lugar a uma nova interpretação de aceitação crescente. $\mathrm{E}$, finalmente, porque o argumento HT oferece um padrão de comparação conveniente para analisar a trajetória que a relação U-E vem apresentando em um país e, em particular, para evidenciar as diferenças entre os que adiante se denominarão pensamentos oficial e alternativo sobre a questão.

A seção que se segue trata do novo argumento sobre a relação U-E que se elabora nos países avançados, apresentando as duas correntes que o conformam — a da "Segunda Revolução Acadêmica" e a que ressalta a importância das relações com o entorno na competitividade das empresas - e a proposição de política — os Pólos e Parques Tecnológicos — delas decorrente. A terceira seção apresenta a interpretação latino-americana acerca da relação $U$-E vigente até o final dos anos 1980, destacando a existência de duas posições acerca da mesma. A quarta trata das mudanças que ocorreram a partir do início dos anos 1990 mostrando como uma dessas posiçôes passa a ser francamente dominante. A última seção comenta o processo de questionamento do argumento HT em curso e as duas visões que nele se expressam.

\section{O surgimento do argumento HT nos países avançados}

Esse argumento, de significativa influência nos estudos sobre a relação U-E e nas recomendações de política dele derivadas, parece estar associado a duas correntes de análise recentemente originadas nos países avançados.

Embora tributárias de enfoques analítico-conceituais distintos, essas correntes apresentam duas características dignas de nota. Primeiro, surgem no interior de uma mesma visão da conjuntura internacional e, também, de uma mesma matriz ideológica que privilegia o mercado como ente regulador principal da relação U-E e, segundo, são francamente complementares.

Sua difusão deu-se de um modo tão penetrante, convincente e apelativo a ponto de erigir o argumento que sustentam em um novo "senso comum" acerca da relação U-E. Elemento indutor desse processo é o fato de que sua construção tem envolvido a formulação de proposições que funcionam ao mesmo tempo como direções de pesquisa da realidade observada, como imagens de um futuro tendencialmente projetado pelos atores envolvidos em 
função do resultado esperado de suas ações, da idealização de processos que julgam ter ocorrido em outras latitudes e, também, como conclusões provisórias que orientam a formulação de recomendações de política. O que faz com que os âmbitos da pesquisa e do policy making se entrelacem, sinalizando suas descobertas e diretivas, e gerando, por um lado, um processo de cooptação da comunidade de pesquisa e, por outro, uma maior direcionalidade e aplicabilidade dos resultados que alcança.

Para uma adequada caracterização do argumento HT convém que se inicie pela apresentação daquelas duas correntes que ganham força no começo dos anos 1990 no debate internacional sobre a relação U-E.

A primeira corrente, focada especificamente nessa relação, tem indicado a existência de transformações de natureza quantitativa e qualitativa na sua dinâmica. Essas estariam ocorrendo no âmbito de um novo contrato social entre a universidade e a sociedade, de uma nova dinâmica na qual seria reservada, à primeira, a função de participar mais ativamente no processo de desenvolvimento econômico.

A segunda corrente, cuja fundamentação é apoiada na Teoria da Inovação (TI), atribui importância fundamental ao processo inovativo que ocorre na empresa e às relaçóes que se estabelecem entre ela e seu entorno como determinante da competitividade dos países. Embora não considere a universidade e a pesquisa básica que ali se realiza como primeiro elo desencadeador de uma hipotética Cadeia Linear de Inovação, como fazem as visões que a antecedem, essa corrente entende que a universidade, revigorada por aquela nova dinâmica, deve ser considerada como um agente privilegiado desse entorno para a promoção da competitividade das empresas e da nação.

Nos três itens que se seguem, procura-se caracterizar essas duas correntes, e a proposição de PCT delas derivada, tal como têm sido referidas nos países avançados pelas contribuições pioneiras e mais destacadas.

\subsection{A primeira corrente: a Segunda Revolução Acadêmica}

Segundo esta corrente, está ocorrendo um processo sinérgico de ampliação quantitativa e qualitativa da relação U-E. Tal como alegam os que com ela se alinham, isso estaria traduzido na existência de um crescente número de contra- 
tos entre empresas e universidades com vistas ao desenvolvimento de atividades conjuntas (Etzkowitz, 1989). Aponta-se, também, para um processo de ampliação qualitativa da relação, caracterizado pelo fato de que estariam ocorrendo atividades com crescente resultado econômico (Etzkowitz \& Peters, 1991).

Segundo Webster \& Etzkowitz (1991), entre as razões que explicariam esta ampliação das relações U-E estariam, do lado das empresas:

- custo crescente da pesquisa associada ao desenvolvimento de produtos e serviços necessários para assegurar posições vantajosas num mercado cada vez mais competitivo;

- a necessidade de compartilhar o custo e o risco das pesquisas précompetitivas com outras instituições que dispõem de suporte financeiro governamental;

- elevado ritmo de introdução de inovações no setor produtivo e a redução do intervalo de tempo que decorre entre a obtenção dos primeiros resultados de pesquisa e sua aplicação;

- decréscimo dos recursos governamentais para pesquisa em setores antes profusamente fomentados, como os relacionados ao complexo industrialmilitar.

Do lado da universidade, as motivações principais seriam:

- a dificuldade crescente para obtenção de recursos públicos para a pesquisa universitária e a expectativa de que estes possam ser proporcionados pelo setor privado em função do maior potencial de aplicação de seus resultados na produção;

- interesse da comunidade acadêmica em legitimar seu trabalho junto à sociedade que é, em grande medida, a responsável pela manutenção das instituições universitárias.

Essa ampliação estaria denotando uma maior eficiência da relação U-E-governo, fruto do estabelecimento daquele novo contrato social entre a universidade e seu entorno que estaria levando a universidade a incorporar as funçôes de desenvolvimento econômico às suas já clássicas atividades de ensino 
e pesquisa, e a redefinir suas estruturas e funções (Etzkowitz, 1994). Estaria ocorrendo, assim, a generalização de um padrão de relação caracterizado pelo maior impacto econômico das pesquisas realizadas na universidade.

Já nas suas primeiras contribuições ao tema, Henry Etzkowitz, um dos autores que mais se tem destacado na exploração dessa temática, enunciava a idéia central que pode ser usada como síntese desta corrente de análise: a de que a universidade estaria vivendo uma "Segunda Revolução Acadêmica", marcada pelo forte sinergismo entre instituições acadêmicas e empresas (Etzkowitz, 1989; Webster \& Etzkowitz, 1991).

Esta corrente apóia-se em resultados de estudos de caso sobre universidades, sobretudo norte-americanas. Ela tem pautado a discussão sobre a relação U-E nos países avançados e influenciado crescentemente a PCT dos EUA e de outros países, que serve de substrato para a construção que aqui se faz do argumento HT.

\subsection{A segunda corrente: a importância das relações com o entorno na competitividade das empresas}

Esta corrente de análise tem como matriz o que se conhece como a Teoria da Inovação. Coerentemente com sua inspiração schumpeteriana, essa teoria, ao considerar a empresa como o locus privilegiado da inovação e o empresário como agente direto do progresso técnico (Dosi, 1982), significou uma substancial transformação nas concepções vigentes acerca do desenvolvimento tecnológico. A identificação do caráter tácito, dificilmente transferível e apropriável do conhecimento tecnológico viria a atuar como um elemento de natureza empírica contrário à racionalidade do modelo linear ofertista, até então hegemônico na elaboração da PCT dos países avançados.

Quando de sua primeira formulação, prevalecia no núcleo dessa corrente a idéia de que o "empresário schumpeteriano", com qualidades excepcionais e com uma postura empreendedora e inovadora intrínsecas, seria capaz de conceber as inovaçôes de caráter radical. Considerava-se, ainda, a existência de dois momentos distintos no processo de introdução do progresso técnico no aparelho produtivo: a inovação, propriamente dita, e a sua difusão.

Nessa concepção de inovação e de empresário inovador havia então pouco espaço para uma política pública que gerasse um ambiente de interação através do 
estreitamento da relação U-E. Embora autores como Christopher Freeman já em meados dos anos 1970 assinalassem a importância da interação entre os atores envolvidos no processo que leva à inovação (Freeman, 1978), seu principal determinante era então associado à atitude empreendedora, capaz até mesmo de superar os obstáculos do contexto e seguir ao longo de trajetórias evolutivas de inovação.

Posteriormente, e a partir da consideração de que o processo inovativo abrangia não apenas aquelas inovações de caráter singular, radical, mas que era um processo contínuo que incluía adaptações e inovações menores (Rosenberg, 1982), aqueles dois momentos distintos — inovação e difusão — passam a ser vistos como imbricados e, no limite, não diferenciados. $O$ conceito de inovação é ampliado, passando a incorporar o de difusão. A aprendizagem decorrente do processo de utilização e adaptação (learning by doing, using, buying, interacting, exporting, etc.) passa a ser considerada como elemento fundamental na aquisição de competitividade pela firma, ao lado de sua capacidade de P\&D formal (Lundvall, 1985). O vetor de competitividade da empresa passa a ser entendido como resultante de sua capacidade de gerar internamente um processo de aprendizado permanente mediante a combinação dos insumos do ambiente externo com aquilo que é insubstituível, que só ela pode realizar — o contato direto com a produção e o mercado (Dosi \& Soete, 1988).

Diferentes autores vão conformando o substrato dessa corrente à medida que prosseguem na análise do ambiente institucional onde ocorre a inovação. Tomar novamente um dos pioneiros desta corrente (Dosi, 1988) parece suficiente para caracterizar a contribuição dos autores que com ela se alinham. Ele destaca, como condições responsáveis pelo contexto inovativo:

- os constrangimentos e as oportunidades tecnológicas;

- as experiências e habilidades incorporadas em pessoas e organizações;

- as capacidades e "memórias" que fluem de uma atividade econômica para outra.

Enfatiza, adicionalmente, que essas condições são:

- específicas para países, regiões e até mesmo companhias; 
- as que conformam no âmbito da firma as oportunidades, estímulos e restrições ao processo inovativo;

- as que definem, ao lado de fatores institucionais, as normas de comportamento, os padrões de seleção ambiental, enfim, as condições do contexto no qual os mecanismos econômicos vão dando lugar aos processos de aprendizado.

De fato, ainda que a empresa continue sendo entendida como o principal agente da inovação, maior importância passa a ser conferida aos fatores de competitividade sistêmica do entorno em que ela atua e onde ocorre em sua integralidade a difusão da inovação. As características do ambiente passam a ser o que determinaria em que medida a empresa seria capaz de participar ativamente do processo inovativo e implementar, no seu próprio âmbito e a partir das suas idiossincrasias, o que até então se percebia como processo de difusão. Essa forma de entender a inovação e seus condicionantes expressa, no nível da interpretação dos processos reais, um aumento do espaço para a intervenção do Estado e para a elaboração de políticas públicas que, a partir da ação nesse entorno, promovam a competitividade (Freeman, 1988).

Outras perspectivas desenvolvidas por autores aqui apenas mencionados, foram adicionando elementos que reforçam a importância das relaçóes entre os atores presentes no ambiente inovativo. Lundvall (1985 e 1988) chama a atenção para os conceitos de relação usuário-produtor. Porter (1990), para os de competitividade sistêmica. Nelson (1993), Lundvall (1992), Niosi et al. (1993), para os de sistema nacional de inovação, e Callon (1992), para redes técnico-econômicas "callonianas". Todos eles, ainda que mantendo a ênfase na empresa, destacam a importância de sua capacidade para estabelecer relações virtuosas com atores que, como ela, estão situados numa complexa malha responsável pela inovação.

A partir dessas contribuiçôes vai-se complexificando e ganhando mais realismo o modelo explicativo adotado para analisar as questôes atinentes à relação U-E. A universidade, que algumas vezes havia sido considerada como celeiro, senão único, indispensável de novas idéias, e como o necessário primeiro elo da Cadeia Linear de Inovação celebrizada pelo seminal Relatório Bush (Bush, 1945), passa a ocupar um lugar mais modesto na rede modelizada como explicação do fenômeno inovativo. 
Entre as várias contribuiçōes importantes que o olhar dos economistas aportou ao tema esteve a preocupação com indicadores de C\&T. Ela decorreu de seu viés profissional que neste caso se refletia em avaliar quantitativamente, no nível macro, a dimensão das relações entre a universidade e as empresas que subjaziam aos estudos de caso que faziam.

Um desses indicadores, produzido pela National Science Foundation (NSF), proporcionou uma informação a respeito da relação U-E até então pouco conhecida e levada em conta pelos policy makers da PCT. Ele corroborava a revisão que a corrente em análise sugeria sobre o papel da universidade. Seus anuários, Science and Engineering Indicators, começaram a mostrar algo, na época surpreendente, que contribuiu para induzir importantes mudanças no comportamento dos atores públicos e privados envolvidos com a relação U-E. De acordo com eles, somente 1,3\% do gasto em pesquisa das empresas norte-americanas era contratado com as universidades (NSF, 1997); 98\% dele era realizado pelas próprias empresas. Esse indicador, que mostra a pequena importância da universidade como produtora de resultados de pesquisa passíveis de serem utilizados pelas empresas para gerar inovação, passou a ser insistentemente apontado para fundamentar a idéia de que pouco se pode esperar do conhecimento intangível que essa relação pode aportar à competitividade dos países.

Mas outros indicadores sugeriam um paradoxo. A proporção dos pesquisadores daquele país que estavam desenvolvendo atividades de $\mathrm{P} \& \mathrm{D}$ na empresa, ou dos doutores formados anualmente que para lá iam (segundo a mesma fonte) estava em torno de $70 \%$. O que estava mostrando que a pesquisa universitária era importante para as empresas. Mas não pelo seu resultado em si, em termos de conhecimento, e sim pelos recursos humanos que permitem às empresas alicerçar suas estratégias concorrenciais em trajetórias de inovação capazes de proporcionar-lhes competitividade nos planos interno e externo. Passou-se, então, a perceber mais claramente que o importante era o conhecimento incorporado em pessoas que, através de um processo de capacitação longo e custoso, bancado naquele país et pour cause pelos cofres públicos, davam o impulso inicial à cadeia de inovação.

Como resultado dessa evolução aqui sinteticamente resumida com o objetivo de explicar o surgimento do argumento HT, a universidade passa a ser 
entendida como um elemento privilegiado do ambiente inovativo. Embora sem ser situada no centro do modelo Sistema Nacional de Inovação — crescentemente adotado em sua acepção normativa —, lugar este ocupado pela empresa, a universidade era considerada como um indispensável fator de competitividade sistêmica e seu desenvolvimento deveria estar crescentemente pautado pelo perfil de egresso demandado (presente e futuramente) pela empresa.

É assim que vão sendo construídas as pontes interpretativas com a corrente da Segunda Revolução Acadêmica. Pelo menos com aqueles que, no seu interior, incorporaram as idéias e comportamentos que a realidade desvendada pelos indicadores de C\&T induzia.

\subsection{A proposição de política: os Pólos e Parques Tecnológicos}

Os ambientes de pesquisa universitária dos países avançados, que desde alguns anos antes haviam internalizado o "Modelo Silicon Valley" e vinham procurando insistentemente emulá-lo, foram o cenário em que se desenvolveram e foram rapidamente adotadas como diretriz normativa as duas correntes de análise acima referidas.

A existência de uma correlação entre esses dois eventos no sentido sugerido pela ordem dessa exposição, embora possa ser verificada empiricamente, não autoriza entre eles o estabelecimento de uma relação causal, temporal, e muito menos teórica. $\mathrm{O}$ fato de que em trabalhos de muitos autores, alguns anteriores ao surgimento dessas duas correntes, como Lafite (1985) e Currie (1985), apareçam referências a partes da argumentação que elas usam pode sugerir um encadeamento temporal inverso. O mais provável é que, como usualmente ocorre, tenha ocorrido uma espécie de co-evolução ou auto-organização. Tentativas de generalização de eventos observados teriam produzido fatos estilizados seguidos de movimentos de teorização que resultaram na codificação dos conjuntos de proposições que aqui se denominaram correntes.

Trabalhos que apareceram simultaneamente ao seu surgimento, como MITI (1990), Lacave (1991), e muitos outros publicados posteriormente parecem seguir uma seqüência indutiva — descrição-análise-prescrição — apoiada naquelas teorizaçōes para recomendar a promoção de mecanismos institucionais tais como, escritórios universitários de transferência de tecnologia e de registro de patentes, 
incubadoras de empresas, centros de pesquisa cooperativa, serviços de identificação de parcerias potenciais no setor produtivo, arranjos para obtenção de capital de risco.

Até mesmo porque englobam muitos desses mecanismos, são os conhecidos como pólos e parques tecnológicos os que mais se destacam. De fato, um movimento de realimentação positiva entre análises da relação U-E e proposição de mecanismos institucionais, de um lado, e avaliações das implicações destes últimos, de outro, têm contribuído para que se passe a entender os pólos e parques tecnológicos como arranjos privilegiados para promover a competitividade dos países avançados (Cox, 1985; Dalton, 1985; Delapierre, 1988; FRANÇA, 1990).

Num quadro como o vigente, em que o elemento indutor do desenvolvimento econômico (e do progresso social) de um país tende a ser reduzido à competitividade de suas empresas, e em que esta é crescentemente interpretada como dependendo da relação U-E, uma decidida atitude pró-ativa de "acadêmicos empreendedores" era de se esperar. Ela se manifestou pela conversão de círculos crescentes de professores, pesquisadores, policy makers, funcionários de várias instâncias e áreas de governo, empresários, etc., à idéia de que o estabelecimento de mecanismos institucionais de interação era uma tarefa coletiva que beneficiaria não apenas a eles próprios — os "acadêmicos empreendedores", que passariam a dispor de maiores recursos - mas o conjunto daqueles atores e a sociedade.

Afinal, tal como apontava um outro indicador proveniente da mesma National Science Foundation, aquele 1,8 bilhão de dólares com os quais a empresa norte-americana financiava projetos de seu interesse na universidade representava somente $7 \%$ de seu orçamento para pesquisa, e apenas algo em torno de $3 \%$ do orçamento total das universidades. Essa situação era vista por muitos como uma oportunidade de captação de recursos que se abria para a universidade. A importância crescente que o governo e a opinião pública conferiam à competitividade e ao alucinante ritmo da revolução tecnológica em curso, passou a reforçar o apelo daqueles arranjos no interior da comunidade universitária.

Adicionalmente, o encurtamento do tempo de maturação das descobertas científicas, que se transformavam cada vez mais rápido em inovações, num gigantesco complexo privado de $\mathrm{P} \& \mathrm{D}$ norte-americano que avançava "perigo- 
samente" em direção à pesquisa básica, aconselhava à corporação universitária, como medida cautelar em defesa de seus interesses, que chamasse para si ao menos uma parte dos benefícios que as novas tendências prometiam.

Duas situações merecem ser citadas com o objetivo de dimensionar o momentum que adquiriu essa dinâmica. No início dos anos 1990, as 20 empresas mais intensivas em $P \& D$ gastavam em pesquisa mais do que a França e a Inglaterra somadas (UNESCO, 1996); dois países líderes em muitos campos da C\&T, que estavam entre os sete que gastavam quase $90 \%$ do dispêndio mundial em pesquisa (NSF, 1997). A segunda situação não é menos impactante. Uma empresa - a norte-americana Bell (Lucent Technologies) — já teve em seus laboratórios 11 prêmios Nobel. O Japão, em comparação, teve também 11, dos quais seis em literatura e paz, e cinco em ciências duras, sendo que três destes foram obtidos por pesquisadores que viviam nos EUA (Waldimir Pirró y Longo em palestra no IG/UNICAMP, 2000).

Outro desdobramento importante ocorreu no nível da docência universitária. De fato, em função do enxugamento das posições de gerência causado pelo abandono do paradigma fordista que eram anteriormente ocupadas pelos egressos das carreiras universitárias de natureza técnica, e sob a égide do conceito de empreendedorismo, criam-se nas universidades cursos e disciplinas orientados a capacitar esses profissionais em gestão de negócios, marketing, etc., de modo a torná-los aptos para constituir microempresas de base tecnológica.

À medida que se vão incorporando a esse movimento formulações que, ressaltando a importância das redes de interação, levam a uma ampliação do conceito de pólos e parques tecnológicos combinando-o, ou sobrepondo-o, a conceitos como distrito industrial ou pólo industrial, ocorre uma valorização crescente de seu impacto. A consulta feita a autores como Roberts \& Wainer (1968), Dorfman (1983), Tesse (1985), Dalton (1985), Shattock (1985), Saxenian (1991), Davis (1992) mostrou como foi ganhando adeptos ao longo do período que vai do final dos anos 1960 ao início dos 1990 o movimento aqui analisado. E como, sob o impacto das duas correntes de cunho mais analítico antes descritas se vai ampliando o espaço institucional de materialização de suas proposições através de arranjos como os comentados.

É desse conjunto de ações aparentemente dispersas e situadas em diferentes instâncias que se vai conformando o argumento HT. O fato de que ele 
permite uma solução de compromisso entre diferentes atores (pesquisadores universitários, empresários, gestores envolvidos com a PCT), um pacote analítico-institucional-operacional que contempla interesses que de outra forma poderiam entrar em conflito, parece estar na raiz do êxito que vem alcançando.

\section{A interpretação latino-americana da relação U-E até o final dos anos 1980}

Os ambientes de pesquisa e da policy making latino-americanos sofreram no final dos anos 1980 o impacto do argumento HT. Para evidenciar a dimensão desse impacto, e da mudança que ele provocou, apresenta-se um rápido resumo das duas interpretaçooes que vigoravam até então. Entre os trabalhos que fazem menção à existência dessas duas interpretações, explicando-as com algum detalhe e mostrando como se dá a sua evolução ao longo do período abarcado por esta e pelas próximas seções, estão Albornoz (1995), Díaz (1997), Dagnino et al. (1998), Montalvo (1998), Thomas (1999), Dagnino \& Thomas (2001).

De um lado, estavam aqueles que, a partir da perspectiva das ciências sociais, mas profissionalmente dedicados às ciências duras, enfatizavam os obstáculos de caráter estrutural, histórico, fruto do tipo de inserção subordinada dos países latino-americanos na divisão internacional do trabalho e decorrentes dos modelos de desenvolvimento — primeiro agrário-exportador e depois de substituição de importações — adotados na região.

De acordo com essa posição, enquanto reformas estruturais não fossem promovidas, o relacionamento entre a universidade e o setor produtivo não lograria efetividade. Isto é, permaneceriam atuando os obstáculos estruturais derivados do caráter periférico e dependente do nosso processo de desenvolvimento, que exacerbavam as diferenças de cultura institucional dos dois atores que deveriam cooperar. Tais obstáculos, que consolidariam um "imediatismo" do lado da empresa e um "diletantismo" do lado da universidade, determinariam, em última instância, a impossibilidade da interação. Embora manifestando diferentes graus de radicalidade com respeito a essa apreciação, autores como Varsavsky (1969), Sabato (1994), Herrera (1975), Sagasti (1978) podem ser agrupados no que se tem denominado Pensamento 
Latino-Americano em Ciência, Tecnologia e Sociedade (Sabato, 1994; Dagnino et al., 1996).

Apesar de sua coerência com a proposta que defendia o pensamento da esquerda no plano econômico e social, decorrente da matriz teórica da Teoria da Dependência em que ambos se baseavam, essa posição não chegou a ser por ele incorporada. Nem mesmo no ambiente universitário, onde ele era mais difundido, essa posição chegou a contrabalançar as idéias que orientavam a PCT. Nem o Modelo Institucional Ofertista Linear que guiava a política científica e a idéia de que os países latino-americanos - latecomers através de uma política tecnológica baseada na transferência de tecnologia poderiam capacitar-se tecnologicamente, foram seriamente questionadas.

Como se verá mais adiante, foi só muito mais tarde, no período mais recente, que algumas das idéias defendidas por essa posição, talvez pela solidez do modelo descritivo que conformaram, talvez pelo agravamento das tendências que já apontavam, conseguiram penetrar nos ambientes de pesquisa e da policy making.

Adeptos dessa posição continuaram postulando a necessidade de efetuar transformações estruturais no nível socioeconômico e político que pudessem engendrar uma demanda por parte do setor produtivo capaz de levar a uma adequada utilização do potencial de pesquisa e formação de recursos humanos gerados no âmbito da universidade e nos institutos de pesquisa públicos. Por adotar um enfoque que privilegia as condicionantes macro, contextuais, da interação e propor a introdução, na agenda do processo de tomada de decisão, de assuntos dificilmente tratáveis mantido o contorno político vigente, essa posição permaneceu no nível das proposições inócuas e de caráter genérico.

Assumindo uma posição que pode ser considerada quase antagônica, estavam aqueles que, em função de suas preferências políticas, experiências profissionais ou enfoques disciplinares, tendiam a se alinhar com o pensamento oficial. Minimizando aqueles obstáculos estruturais de natureza macro e acreditando que a ampliação da relação U-E era mais uma questão de uma adequada gestão que a promovesse, consideravam que era possível emular as trajetórias virtuosas protagonizadas pelos países avançados. Subestimando, em relação à primeira posição, aspectos de naturezas macro, histórica, estru- 
tural e contextual, esta segunda posição problematizava a questão numa perspectiva micro, conjuntural, incremental e pontual (Figueiredo, 1972; Cruz, 1977; Almeida, 1973).

Na sua versão mais propriamente acadêmica, esta posição adotava (e nele se apoiava) o enfoque disciplinar de Administração de Empresas. Embora utilizando o instrumental dele derivado, ela não possuía um viés propriamente analítico. Seu foco estava em formular recomendações de política (ou, mais propriamente, de gestão) visando implementar mecanismos institucionais que tornassem mais eficaz a relação U-E. Por isso, os representantes desta segunda posição concentravam-se na formulação de recomendações visando à otimização imediata, no plano da gestão, dessa relação. Provavelmente por essas razões, esta posição não chegou a gerar neste período uma produção acadêmica com características semelhantes às da primeira. Na seção seguinte, em que se analisa como essas posições se expressaram na conjuntura dos anos 1990, são comentadas, com apoio em contribuições alinhadas com esta segunda posição, algumas outras características que a conformam.

Por trazerem ao cenário do processo decisório proposições de policy aparentemente depuradas de seu conteúdo de politics, os partidários dessa posição tenderam a ocupar um espaço crescente nesse cenário e, principalmente, no ambiente acadêmico que com ela se relacionava. Por isso, é nos documentos oficiais que transparecem as idéias e proposições defendidas por esta posição.

Faltava a essa posição, quando comparada com a anterior, provavelmente devido a matriz disciplinar que adotava, um modelo descritivo detalhado, que incorporasse o contexto socioeconômico e político em que se inseria a problemática científica e tecnológica. E que através de uma retrospectiva histórica de como eles se haviam relacionado até então, possibilitasse derivar consideraçôes normativas mais abrangentes. Essa carência, entretanto, não chegava a perturbar suas atividades de pesquisa ou suas ações enquanto gestores da relação U-E. Na realidade, essas ações, como se apontou, dado o seu caráter otimizador, incremental, prescindem dos elementos de natureza contextual recém-comentados. De qualquer forma, a própria inexistência de um modelo mais articulado era de certa forma uma vantagem. Ela facultava a introdução ad hoc de elementos do modelo formulado pela posição anterior, sempre que considerado necessário, no marco da situação tratada. 


\section{A interpretação latino-americana nos anos 1990}

A estilização apresentada na seção anterior foi redesenhada a partir do início dos anos 1990 em função da influência do argumento HT. Esta seção tem por objetivo caracterizar esse processo.

Fruto da significativa mudança que se expressa no nível da condução da política pública, o giro interpretativo e normativo que se verificou deu-se em detrimento do papel do estado. Estado que até então se situava, não por acaso, no vértice superior do "Triângulo de Sabato" (Sabato \& Mackenzie, 1982): a versão latino-americana mais simples daquilo que em três dimensões foi posteriormente designado nos países avançados como "Hélice Tripla". Esta situação exemplifica como mudanças no "plano do real" podem prontamente influenciar o "plano da análise" (Sutz, 2002; Kreimer, 2002).

A mudança no quadro das interpretações ou modelizações referente à relação U-E até então conformado por aquelas duas posições se inicia no interior daquela última posição. Já então dominante no plano analítico, e praticamente hegemônica no da politics da C\&T, ela endossa, por razões fáceis de entender, esse argumento. Freqüentemente nele apoiaram, mesmo quando este se encontrava ainda em processo de construção, as premissas ou conclusões provisórias que orientaram a realização dos estudos que produzia. No plano da PCT, ela passa a propugnar ainda com mais força, e agora com um sólido argumento de autoridade, a proposição de política dos "Pólos e Parques Tecnológicos" (Torkomian, 1992; Segatto, 1996; Medeiros, 1990; Marcovitch, 1999; Grynszpan, 1999).

Para mostrar como ocorre essa mudança, e antes de caracterizá-la com mais detalhe, é conveniente apresentar alguns elementos do processo de transformação que ocorre no contexto em que se dá a formulação da política concernente à relação U-E e a própria reflexão sobre esta relação. Seu aspecto mais marcante é a desregulamentação da economia e a crescente exposição da indústria local à concorrência externa. Um dos argumentos favoráveis à implementação de tais medidas, que toca diretamente a questão da relação U-E, é que a exposição do setor produtivo à concorrência externa causaria impactos positivos na competitividade das empresas.

Essa situação originou uma percepção no âmbito da comunidade uni- 
versitária, já então submetida a uma progressiva restrição orçamentária, de que a magnitude da mudança em curso exigia ajustes importantes em seu comportamento. De modo a potencializar o impacto positivo esperado das medidas que visavam à abertura econômica, desmontando o aparelho protecionista do modelo de substituição de importações, foram sugeridas pela comunidade de pesquisa e pelos policy makers, e depois, de forma crescente, pelos empresários, medidas de política de inovação que buscavam promover a competitividade da empresa local. Seu objetivo era a criação de uma nova dinâmica que, a partir das "empresas de base tecnológica", viria a impactar outros atores envolvidos com o processo inovativo, entre eles, e principalmente, a universidade.

Servia como seu fundamento a proposição de que a exposição das empresas locais à competição internacional as estimularia a buscar conhecimento produzido na universidade. De considerável apelo intuitivo, mas ainda carente de verificação analítica e de base empírica que possam validá-la em situações como a brasileira, essa proposição tem sido amplamente incorporada ao discurso oficial. O PICE (1992) e o PCI (1991) são exemplos de documentos oficiais que utilizam, como fundamento dessa proposição, argumentos colocados, na realidade, como hipóteses de trabalho em estudos realizados nos países avançados.

Muitos programas envolvendo órgãos governamentais, empresas e universidades, como o SOFTEX, o PBQP (Programa Brasileiro de Qualidade e Produtividade), o PADCT (Programa de Apoio ao Desenvolvimento Científico e Tecnológico), podem ser citados como exemplos de iniciativas que tiveram por base essa proposição. Elementos que foram a ela associados, provenientes da reflexão levada a cabo nos países avançados sobre sua própria experiência, como a redução da noção de competitividade ao seu aspecto de ocupação de nichos de mercado internacional em detrimento da ocupação e aproveitamento das oportunidades do mercado interno, a ênfase dada ao empreendedorismo, à capacitação em gestão de negócios e marketing, às microempresas de base tecnológica, são facilmente encontrados, servindo de suporte e conferindo à referida proposição status de modernidade e argumento de autoridade (Stefanutto, 2003; Darós, 1997; Barrella, 1998).

Aquela proposição geral, de que a exposição das empresas locais à com- 
petição internacional as estimularia a buscar conhecimento produzido na universidade, também presente entre esses elementos, ocupou um lugar importante na produção acadêmica que adota o enfoque disciplinar da Administração, identificada na seção anterior com o que ali se referiu como a segunda posição sobre a questão da relação U-E. Apenas para citar um de seus mais conhecidos integrantes pode ser apontada a contribuição de Plonski (1990, 1995, 1996) como exemplo de processos bastante freqüentes, em que, como num ciclo retroalimentado, hipóteses de trabalho ganham caráter de verdade inquestionável.

Sensíveis a essa conjuntura, os pesquisadores da relação U-E passam a adotar esse conjunto de proposições com o objetivo de sugerir medidas de política, seja no plano da universidade, seja no do sistema de C\&T como um todo. Como era de esperar, esse esforço desenvolvido no ambiente acadêmico local foi influenciado pelas correntes de análise e os argumentos sobre a relação U-E concebidos no ambiente internacional. Tal influência é caracterizada em Dagnino et al. (1996) pelo seu resultado: pela transição de uma política vinculacionista, baseada na iniciativa das empresas e dos mecanismos governamentais de interface - institutos de P\&D — para uma outra, de caráter neovinculacionista, cuja responsabilidade de implementação recai sobre a universidade.

A exposição dos pesquisadores da relação U-E e da comunidade de pesquisa às duas novas correntes de análise que conformam o argumento HT resultou na sua incorporação a suas análises acerca das transformações que vêm marcando as políticas econômica, industrial e de comércio exterior brasileiras, e da crescente importância que assume a capacidade inovativa na determinação da competitividade. Isto produziu no ambiente local uma diminuição da polarização expressa por aquelas duas posições e levou, como se verá adiante, a uma considerável convergência no plano do diagnóstico.

Não obstante, em função da maior atenção que aquelas correntes conferem à formulação de recomendações de política que estimulem trajetórias que percebem como desejáveis, seus argumentos tenderam a ser aceitos e apropriados com maior vigor, como já apontado, pela segunda posição. Foi, assim, no âmbito desta segunda posição, que a maioria dos trabalhos sobre a relação U-E que adotavam o argumento HT foi gerada. 
Coerentemente com o enfoque disciplinar da Administração de Empresas que adotam, esses trabalhos (Castro \& Balán, 1994; Cerantola, 1993; Quirino, 1993; Stal, 1993; Weiss, 1993; Takayanagui, 1995) costumam usar o estudo de caso como ferramenta heurística — com foco na realidade da empresa - para analisar seu objeto de pesquisa, a relação U-E. O procedimento que utilizam para validar hipóteses, algumas vezes adotadas como fatos estilizados, ou quase-evidências, e outras vezes de forma apenas implícita, envolve uma tentativa de generalização pela via indutiva, dos resultados qualitativos (isto é, sem quantificação) encontrados no nível micro em que são analisadas as experiências de interação U-E. Por buscarem a otimização de aspectos e processos diretamente relacionados à gestão organizacional, não têm porque se preocupar em construir uma "ponte" indutiva entre os níveis micro e macro, o que para muitos economistas, e também para os alinhados com a primeira posição, é considerado como essencial. Finalmente, e devido ao enfoque empregado e ao pragmatismo que obriga essa mesma orientação otimizadora, aqueles trabalhos não costumam praticar a mediação metodologicamente recomendada, e aceita pela primeira posição, entre os momentos de descrição, explicação e prescrição, o que obrigaria a uma análise mais circunstanciada e contextualizada, capaz de testar as hipóteses que, na verdade, aceitam, como destacado, como proposições ou argumentos de autoridade (Gomes, 1999).

Como resultado da atuação desse conjunto de fatores, é conformado um tipo particular de abordagem. Sua aplicação gera recomendações de política pública visando à ampliação da relação U-E que, como seria de esperar, são similares àquelas formuladas pela contribuição de autores dos países avançados. O fato dessa abordagem, tal como observado, não respeitar a seqüência indutiva - observação-análise-prescrição - empregada inclusive na pesquisa que originou o argumento HT a qual, paradoxalmente, inspira a realização de seus trabalhos, torna especialmente difícil a interlocução entre as duas posições.

Assim, embora se assemelhem, no que respeita às características de problem orientation e policy orientation, aos estudos desenvolvidos por outros tipos de enfoques analítico-conceituais, que buscam estabelecer mediações entre os fenômenos diretamente observados e outras realidades adjacentes e o contexto mais geral, esses trabalhos, por se restringirem às ferramentas descritivas de sua disciplina, não conseguem dar conta da complexidade do objeto analisado. 


\section{Discussão}

A PCT brasileira tem sido marcada no passado recente pelo questionamento, por parte do pensamento oficial, do "primeiro elo" da Cadeia Linear de Inovação, aquele que supõe que a simples capacitação de recursos humanos e a pesquisa básica levariam por si só ao desenvolvimento tecnológico. Isto é, seria através da acumulação de "massa crítica" em pesquisa e em recursos humanos que, por um efeito de "transbordamento", se lograria o desenvolvimento tecnológico. Este questionamento, com um atraso de mais de dez anos em relação às críticas formuladas pela Teoria da Inovação concebida nos países centrais, e de mais de 30, relativamente a aspectos levantados pelo anteriormente mencionado Pensamento Latino-Americano em Ciência, Tecnologia e Sociedade, incorpora algumas das idéias centrais por eles desenvolvidas.

Não há duvida, entretanto, que esse questionamento foi catalisado pela reflexão provocada pelo argumento $\mathrm{HT}$, e que é ele o pano de fundo sobre o qual pode vir a se projetar um debate efetivo entre o que hoje poderia ser assimilado àquelas duas posições cuja evolução se acompanhou nas duas seçôes anteriores e que, de fato, devido inclusive a uma correlação de forças francamente desfavorável à primeira delas, nunca chegou a ocorrer de forma sistemática e produtiva.

A segunda posição, à qual se fará referência como pensamento oficial por oposição ao pensamento alternativo derivado da primeira posição, foi a que inspirou a PCT implementada no período 1994-2002. Esse pensamento oficial chega ao momento atual dotado de modelos - descritivo, normativo e institucional - do ambiente da C\&T nacional francamente dominante. Esses modelos não parecem ter-se alterado no governo atual. Algumas razões conjunturais conhecidas que não vêm ao caso comentar e, fundamentalmente, o fato da coalizão de esquerda não ter amadurecido uma proposta de governo para a área de C\&T coerente com as transformações que pretende desencadear no plano econômico e social explicam essa situação.

Dada a precariedade que o reduzido espaço de tempo decorrido desde o início do atual governo impõe a uma análise prospectiva, e devido às características deste trabalho, não é possível fazê-la aqui. Nesse sentido, o que a seguir se apresenta é tão-somente um diagnóstico acerca da trajetória recente do entorno 
econômico-social que envolve a relação U-E necessário para situar a evolução desta relação. Existe um grau razoável de concordância acerca desse diagnóstico entre o pensamento oficial e aquele alternativo que, tendo como matriz a primeira posição antes referida, tem-se expressado em círculos restritos, no âmbito da coalizão de esquerda que hoje ocupa o governo. É dado que existem consideráveis discordâncias expressas por esse pensamento alternativo, que digase de passagem não tem logrado influenciar o processo de formulação da política no âmbito daquela coalizão. Elas se referem, por um lado, às políticas implementadas pelo governo passado e, por outro, às atualmente em curso.

Após a apresentação desse diagnóstico, são comentados alguns aspectos da proposta que orientou a política seguida no governo Cardoso para atuação frente à relação U-E. O fato dessa proposta, embora alinhada com o pensamento oficial, ter-se mantido na agenda do atual governo, levou a que fossem incluídas algumas observações críticas à forma como as políticas vêm sendo hoje implementadas.

Pelas razões já apontadas, esta seção de discussão não inclui uma apresentação das alternativas que vêm sendo concebidas e apresentadas em documentos de natureza político-partidária e em artigos de divulgação orientados à comunidade de pesquisa. Sua intenção é apenas situar algumas tendências cujo desenvolvimento poderá gestar cenários alternativos a serem considerados para elaborar medidas de política atinentes à relação U-E.

\subsection{O diagnóstico da situação econômico-social e a relação U-E}

Tal como ocorreu na seção anterior, aqui se procura explicar a emergência do pensamento oficial sobre a relação U-E que, pouco a pouco, se vai convertendo num novo senso comum que transparece, inclusive, no discurso do governo atual, e se apresenta alguns aspectos da dinâmica observada no campo econômico e social. Essa caracterização da dinâmica do contexto em que se insere a relação U-E se inicia pela questão da produção industrial, do emprego e da tecnologia.

O que parece estar ocorrendo no País, com respeito a essa questão, é uma diminuição relativa do tamanho econômico do setor industrial nacional, tanto no que tange ao emprego como no que respeita ao volume do capital fixo e 
circulante, como conseqüência da rápida introdução de novas tecnologias no processo de produção e circulação de mercadorias (incluída aí a nova forma de organização do processo de trabalho). Tal processo possui uma intensidade variável, em função do grau em que o segmento econômico nacional se assemelha ao seu homólogo nas sociedades avançadas. Isto é, segmentos onde a difusão dessas tecnologias ocorre lá com maior intensidade e rapidez tendem a transformar-se aqui de forma análoga. Especialmente, e não por acaso, aqueles em que empresas multinacionais são claramente dominantes e que, através do fluxo de tecnologia intramuros, aceleram essa difusão.

Alguns indicadores podem ser apresentados para ilustrar o processo em curso.

Entre 1991 e 2000, no País:

- do ponto de vista quantitativo, o crescimento econômico médio anual foi inferior a $2 \%$ e, dado que empregar os que chegam ao mercado de trabalho (1,5 milhão por ano) exige uma taxa anual superior a 5,5\%, deixaram de ser criados 3,2 milhôes de postos de trabalho formal;

- do ponto de vista qualitativo, o coeficiente importação/consumo de bens industriais passou de 6 a 15\% (o de material de transporte de 5 a $23 \%$ e o de eletroeletrônicos de 10 a 66\%) indicando que em segmentos como esses houve uma substituição dos empregos brasileiros com um certo nível de salário (e "qualificação") pelos gerados no estrangeiro.

No País, atualmente:

- entre as 500 maiores empresas, as de propriedade estrangeira, situadas em segmentos especialmente intensivos em tecnologia, são responsáveis por $46 \%$ da produção (quando, em 1985 respondiam por 29\%), o que mostra um quadro de quase irreversibilidade do desemprego, mesmo caso venha ocorrer uma retomada do crescimento econômico;

- também entre as 500 maiores empresas, as de propriedade estrangeira controlam $92 \%$ do segmento de eletroeletrônicos, $85 \%$ do de automóveis, 78\% do de computação e 74\% do de telecomunicações, o que mostra que ao serem pressionados por um esperado aumento de 
demanda, esses segmentos, já intensivos em tecnologia, irão modernizarse ainda mais sem que se verifique um aumento substantivo no emprego.

Mas, de 1980 a 2001, os bens de consumo durável produzidos nesses segmentos tiveram seu consumo ampliado (as famílias que possuem televisores e geladeiras passaram de $55 \%$ e $50 \%$ para $87 \%$ e $84 \%$ ) graças a uma redução de seu preço real de $50 \%$. Parecem ser a causa dessa evolução positiva para essas famílias, a redução das alíquotas de importação e o aumento da participação das empresas estrangeiras no mercado.

De fato, a atual maior velocidade com que esses segmentos (e o de bens duráveis de consumo é o seu arquétipo) aumentam sua eficiência técnica lhes permite uma enorme redução dos custos de produção. Em nosso país, ao contrário do que ocorria no passado, ela hoje tende a ser repassada ao preço que praticam. A concorrência dos produtos importados passou a ter importância significativa nesse sentido.

Há aqui efeitos que tendem a se contrabalançar numa proporção variável no tempo e em cada segmento. Diminui o emprego e a massa de salários (ainda que em menor proporção) e diminui o preço real desse tipo de bens (duráveis de consumo), o que tende a levar a uma maior demanda dos mesmos. Potencializa esse processo a queda do preço relativo de alguns bens salário (de consumo não-durável). $\mathrm{O}$ fato de que a diminuição do preço relativo dos duráveis de consumo tem causado um efeito renda agregado maior do que aquele, negativo, que o desemprego tem provocado explicaria a convivência do desemprego massivo com o aumento, por exemplo, da proporção de domicílios que possuem televisão e geladeira. Há que se somar a esse quadro o impacto das atividades informais que contribuem para amenizar o efeito renda negativo recém apontado. Iniciativas distributivas atuam no mesmo sentido e podem provocar um dinamismo econômico mesmo num quadro geral recessivo.

Entrando na questão tecnológica que conduzirá à da relação U-E, cabe destacar que:

- entre 1992 a 1997, quando o PIB aumentou 23\% a importação de tecnologia (licenciamento, patentes, etc.) cresceu 1.000\%; mas que,

- ao contrário do que ocorre nos países emergentes da Ásia, onde 
importação de tecnologia alavanca P\&D local e promove o aumento da produção e exportação de bens intensivos em tecnologia, isso não ocorreu aqui;

- entre 1990 a 2000 o déficit de nossa balança comercial desse tipo de bens com os países avançados aumentou nove vezes;

- o que indica, tal como se tem observado em outros países latinoamericanos, uma sensível "especialização" da região em produtos com pouca tecnologia incorporada.

Entrando agora no campo da relação U-E, é conveniente citar alguns outros fatos estilizados e indicadores que contribuem para justificar as consideraçôes que se apresentam no próximo item. Juntamente com os fatos e indicadores anteriormente destacados, eles parecem apontar para uma diferença entre as características que possuem em nosso país os arranjos institucionais e os comportamentos dos atores presentes no campo da relação U-E vis-à-vis o panorama internacional. Os indicadores que vale a pena destacar, e que como os anteriormente apresentados possuem marcada atipicidade quando comparados com os dos países avançados e emergentes asiáticos, e clara relação com nossa situação periférica, são os seguintes:

- notoriamente reduzidos indicadores relativos (ao PIB, ao dispêndio nacional em C\&T, ao faturamento) de dispêndio em P, D\&E da empresa privada (a nacional, devido à nossa situação economicamente periférica e culturalmente mimética, e as transnacionais por razões também conhecidas);

- desinteresse da empresa local por atividades de P\&D (71\% das incluídas em uma amostra representativa declararam que a aquisição de máquinas e equipamentos mais atualizados é a sua principal estratégia de desenvolvimento tecnológico);

- desinteresse da empresa local, também economicamente racional e compreensível, pela absorção de pesquisadores (3\% apontaram essa estratégia, em 8- e penúltimo lugar);

- baixa utilização pela empresa local das universidades e institutos de pesquisa públicos (citados em 10 e 11\%, penúltimo lugar, entre as fontes de conhecimento utilizadas); 
- baixa capacidade de absorção de pessoal pós-graduado pela empresa privada (numa amostra de outra pesquisa, de 70.000 empresas, existiam menos de 1.000 doutores em tempo integral equivalente em atividades de P\&D, enquanto de 1980 a 2000 o número de doutores formados anualmente aumentou de 500 para 6.000 e segue aumentando a uma taxa anual de 10\%);

- conseqüente dificuldade em potencializar a capacitação científica do complexo público das universidades e institutos de pesquisa em produção tecnológica na empresa privada (os indicadores respectivos usuais, de artigos publicados e patentes registradas nos EUA anualmente mostram que entre 1980 e 2000, enquanto no plano científico tivemos evolução semelhante à da Coréia — passamos de 1.900 para 9.500 artigos, e a Coréia de 230 para 12.200 — no plano tecnológico nosso desempenho foi sofrível: fomos de 23 para 98 patentes, e a Coréia de 17 para 3.300) (Brito Cruz, 2002);

- potencial de mobilização da capacidade de pesquisa universitária pela empresa privada provavelmente ainda menor do que o observado em países como os EUA (onde apenas 1,7\% do que a empresa privada gasta em P\&D é contratado com a universidade);

- potencial de captação de recursos pela universidade via contratação de projetos de pesquisa com a empresa privada provavelmente ainda menor do que o observado em países como os EUA (onde apenas 3\% do orçamento da universidade provêm desta modalidade de pesquisa);

- pouco comum e crescente hipertrofia do ensino superior privado (sua participação no total de vagas, entre meados dos anos 1960 e hoje, passou de menos de $40 \%$ para mais de 60\%, o que coloca o País em 8 lugar no ranking de privatização do ensino superior, vindo na frente dos EUA que se situa em $20^{\circ}$ );

- aguda diferença de qualidade existente entre o ensino superior público e o privado;

- extrema concentração das atividades de pesquisa e pós-graduação na universidade pública;

- provável ampliação do ensino superior público com mudança significativa de suas características e do modelo até agora adotado, a julgar pela 
extremamente reduzida, mesmo em comparação com outros países periféricos, parcela dos jovens entre 18 e 24 anos matriculados no ensino superior (ela é de $8 \%$ no País e chega a $80 \%$ no Canadá) e ao grande contingente de egressos do ensino médio de baixa renda que passarão a pressionar a universidade pública;

- considerável perda de legitimidade social da universidade pública, devido à limitada chance de mobilidade social que oferece à classe baixa, escassa relevância da pesquisa que desenvolve, tanto para esta como para o empresariado, o que reduz sua capacidade de negociação na alocação de recursos nos níveis federal e estadual.

\subsection{A política em curso}

Este item comenta, a partir da perspectiva do que se referiu acima como pensamento alternativo, alguns aspectos da política seguida no governo Cardoso no que respeita à relação U-E, e que parece ter-se mantido no governo atual. Ainda mais do que o item anterior, este item possui um estilo mais politizado e menos "acadêmico" que destoa das partes iniciais deste trabalho. Espera-se que este estilo, que por razóes evidentes pareceu inevitável, seja aceito pelo leitor.

A gestação de um novo modelo institucional que servisse de suporte às transformações estruturais que o governo passado supunha necessárias foi ocorrendo de forma paulatina, ao sabor das oportunidades que se abriam no plano político e, freqüentemente, através de declarações e ações contraditórias.

Entre esses arranjos institucionais, pelo seu caráter arquétipo e pelo fato de ter obtido maior grau de implantação que outros, como a Lei de Inovação, os Fundos Setoriais merecem ser analisados com algum detalhe. Talvez caiba explicar, adicionalmente, a intenção de incluir aqui as considerações críticas que seguem, relativas à forma como os Fundos Setoriais foram concebidos e têm sido manejados pelo atual governo: elas são um bom exemplo do tipo de trabalho que vem desenvolvendo aquele pensamento alternativo e do posicionamento que ele tem assumido em relação às proposições contidas no "argumento HT".

Resultado da tentativa do Ministério da Ciência e Tecnologia (MCT) de recuperar o montante aplicado em C\&T, reduzido por sucessivos cortes e “contingenciamentos", seu objetivo era a arrecadação de recursos públicos prove- 
nientes de impostos e contribuições de alguma forma resultantes de atividades econômicas de atores que, pelo menos teoricamente, estariam interessados em utilizar resultados da P\&D a ser financiada. Os Projetos seriam executados fundamentalmente por universidades e centros de pesquisa, usando recursos públicos a fundo perdido para alavancar a lucratividade das empresas privadas neles interessadas.

Os processos de negociação que originaram os hoje 14 Fundos foram bastante distintos, dado que resultaram da identificação de oportunidades, num processo pouco sistemático e racional. Em alguns casos, como o de setores mantidos sob controle estatal, como o do petróleo, a criação do Fundo respectivo foi, por isso mesmo, fácil; e imediata a sua entrada em funcionamento. $\mathrm{Na}$ verdade, ele envolveu apenas um novo arranjo para a alocação dos recursos para a P\&D, anteriormente centralizada pela Petrobras. A alocação passou a ser feita através de editais (mediante a aplicação de critérios nem sempre consensualmente aceitos, como os de reservar uma parte dos recursos para os estados do nordeste) e implicou a participação de uma maior quantidade de atores, inclusive de empresas. Análises disponíveis sobre os resultados do primeiro Edital do CT-PETRO (Fundo Setorial do Petróleo e Gás Natual) mostram o que desde o início se podia prever: cerca de $80 \%$ dos recursos foram utilizados pela própria Petrobras. Situação até certo ponto semelhante ocorreu com o CPqD em relação ao FUNTTEL (Fundo para o Desenvolvimento Tecnológico das Telecomunicações) que, embora não sob a responsabilidade do MCT e sim do Ministério das Comunicações é considerado como pertencente ao arranjo Fundo Setorial. Em suma, pouco parece ter-se avançado nestes dois casos em relação ao proposto pelo argumento HT no que respeita à recomendação de estreitar os laços entre a universidade e a empresa privada.

A maior parte dos Fundos, entretanto, não chegou a entrar em funcionamento durante o governo passado, dada a dificuldade em convencer os atores responsáveis pela constituição dos fundos de recursos e da sua aprovação pelo Legislativo. Isto permite afirmar que a pretensão do MCT de recuperar o nível de dispêndio real em C\&T encontra-se ainda distante de ser efetivada. Tanto mais que, ao contrário do insistentemente publicado, eles não são "blindados" contra contingenciamento por parte da "área econômica" do governo.

Mas, mais do que isso, é importante ressaltar que sua criação obedeceu a 
um imperativo de ordem política ligado à viabilidade de que os recursos para a sua constituição fossem considerados rentáveis, em termos dos resultados de P\&D passíveis de serem produzidos, pelos atores que os liberariam.

Como apontado acima, não é possível encontrar racionalidade e intencionalidade na atuação do MCT em relação aos Fundos. Pelo contrário, eles revelam um comportamento que os policy analysts costumam denominar "não-política". Isto pode ser avaliado, em primeiro lugar, levando em conta o critério presente na negociação dos Fundos: o montante da contribuição seria proporcional ao tamanho econômico do setor. O procedimento não demonstra uma disposição de planejar e nem mesmo parece corresponder à realidade da relação P\&D-produção: nem nacional, nem a observada internacionalmente. Tomando por base o que ocorre nos países avançados, onde a porcentagem do faturamento destinada à $\mathrm{P} \& \mathrm{D}$ nos vários setores econômicos é extremamente variável (varia numa proporção de 1 a 20) pode-se ver o quão artificial é o procedimento adotado. $\mathrm{O}$ fato de que essa variabilidade se deva a razóes de tipo "estrutural" (características técnicas fazem com que eles não demandem conhecimento novo na mesma proporção) e "conjuntural" (os setores onde é maior a expectativa de lucro futuro são aqueles que mais investem em pesquisa), ilustra o apontado acima.

Em segundo lugar, pelo fato de que nos países avançados, onde a maior parte do gasto em P\&D é das empresas, quando o governo intervém (mediante fomento direto, renúncia fiscal, ou poder de compra) é para alavancar de modo diferenciado, por razóes, econômicas, sociais, ambientais ou geopolíticas, o crescimento futuro de setores que considera “estratégicos”. Lá, portanto, dificilmente se tomaria como critério de fomento à pesquisa o tamanho econômico do setor a privilegiar!

Esses aspectos, e a percepção de que arranjos institucionais internos ao aparelho de estado e o seu relacionamento com outras organizações não são entidades neutras é o que levou aquele pensamento alternativo a aconselhar uma profunda análise deste arranjo institucional ao novo governo. Isto porque, se sua orientação é no sentido de negar uma adaptação passiva ao mercado e promover um estilo de desenvolvimento social, econômica e ambientalmente sustentável para todos, mudanças na Política de C\&T que desta decorrem e que se necessita para alavancá-lo, terão que ser implementadas. E, em conseqüência, 
alterações no quadro institucional teriam que ser desencadeadas de modo a adaptá-lo a um objetivo significativamente distinto.

O resultado do Grupo de Trabalho (GT) criado já no atual governo para analisar os Fundos Setoriais - o relatório que apresentaram - merece ser também comentado com algum detalhe. Isto porque, por um lado, ele parece corroborar o que se apontou acima a respeito da manutenção, pelo atual governo, de aspectos centrais do marco de referência que orientou a política seguida no governo anterior para atuação frente à relação U-E. Por outro lado, porque o comportamento do GT, por nele participarem pessoas pertencentes a círculos muito variados (acadêmicos, empresários, sindicalistas, gestores públicos) pode ser tomado como representativo desse processo. E, adicionalmente, porque, ao criticar o Relatório do GT se está sendo coerente com o que se apontou anteriormente, acerca da pouca legitimidade que teria uma crítica a uma gestão que apenas se inicia.

A primeira sugestão contida no Relatório apresentado pelo GT é a de "utilização dos fundos no estímulo direto à ampliação das atividades de P, D \& I nas empresas de base tecnológica e prioritariamente de capital nacional".

A sugestão implica uma verdadeira revolução mundial em termos de política de C\&T. Salvo engano, nenhum país financia a fundo perdido a P\&D de empresas estrangeiras. E não deixa de ser estranho que justamente um governo comprometido com a defesa dos interesses nacionais promova essa mudança institucional na C\&T brasileira. O fato de que nossa Constituição não diferencie as empresas pela propriedade do capital fará com que, ao negligenciar as universidades e instituiçóes de pesquisa, as empresas transnacionais se tornem beneficiárias privilegiadas dos Fundos. Como se sabe, elas possuem uma capacidade muito maior do que as nacionais de ter acesso a recursos públicos (atendimento a editais, elaboração de projetos, "contatos", etc.), de dialogar produtivamente com aquelas instituições, de demandar o pessoal qualificado que a duras penas formamos. E, por mais que se adicione advérbios como "prioritariamente", seria ingênuo pensar o contrário. E note-se que não se está aqui falando do que foi denunciado no passado acerca do uso, pelas empresas transnacionais aqui sediadas, para outras finalidades dos recursos que a renúncia fiscal facultava para aplicação em P\&D.

Não parece ser necessário, para estimular as empresas a inovar, negligenciar, nos Fundos Setoriais, as universidades e as instituições de pesquisa. Por um lado, 
porque existem outros mecanismos para tanto. Por outro lado, porque ao fazê-lo se estará eliminando uma preciosa possibilidade de assessment do uso de recursos públicos por instituições que, com exceção das PUCs, são públicas. Capacidade de assessment que, diga-se de passagem, o antigo MCT reconheceu não mais existir no aparelho de um estado dilapidado, ao ter que estimular a criação de uma organização social para tanto. A qual, ironicamente, só pode cumprir suas funçōes apoiando-se na competência instalada naquelas instituições públicas.

Se a idéia é evitar os vieses corporativos e "ofertistas" dessas instituições, como muitas vezes se diz (e é necessário fazer), e "pragmatizar” e potencializar nossa capacidade de produzir e difundir conhecimento, "a emenda pode ser pior do que o soneto". A única maneira de "ganhar" a comunidade de pesquisa para um projeto de sociedade economicamente viável e socialmente mais justo é promover um processo de discussão sistemático sobre a sua agenda de pesquisa. Sem uma comunidade de pesquisa consciente e engajada, o País não vai longe. Com ela, o Estado pode ter um parceiro qualificado e íntegro para apoiar com eficácia, de forma descentralizada, espacial e setorialmente, e diretamente ligada ao processo de $\mathrm{P} \& \mathrm{D}$ em que devem participar atores privados, o gerenciamento $\mathrm{e}$ controle dos Fundos públicos. Mas para isso é necessário ter vontade política para mudar; e mudar numa direção coerente com as condiçóes que temos e o cenário que queremos construir.

A sugestão, ao mencionar "empresas de base tecnológica", não especifica se está se referindo a empresas intensivas em tecnologia em geral ou a empresas que surgem como spin offs da pesquisa universitária. Em qualquer dos casos caberia explicitar a razão do privilégio que propõe sob pena de ser interpretada como um modismo mimético lamentável, típico do senso comum mal informado. Que critérios a informam? Qual é o tamanho (e impacto) econômico relativo desse tipo de empresas no tecido produtivo brasileiro vis-à-vis àquele que possuem em países avançados onde têm sido alvo de programas de fomento específico? Em que setores se localizam? E porque não privilegiar na alocação de recursos dos Fundos Setoriais as empresas "sem base tecnológica", que atendem mercados muito mais significativos que talvez possam responder muito melhor, em termos de impacto social e econômico, ao investimento público em P\&D?

A segunda sugestão do Relatório, "criação de mecanismos que permitam a implantação de equipes de P, D \& I nas empresas através de política de crédito e 
concessão de bolsas para fixação de pesquisadores nas empresas" colocada logo depois da anterior, dá uma impressão de ser o assoprão que se dá depois do beliscão. Por um lado, afasta-se a universidade do circuito de fomento. Por outro, busca-se criar condiçôes para permitir que a comunidade universitária siga pesquisando o que deseja e formando os mestres e doutores com o perfil que considera "de qualidade" e que para tanto realize a pesquisa que lhe pareça, garantindo que esse pessoal escape do desemprego ou do brain drain. Não importa se para beneficiar o capital estrangeiro, nacional, grande, pequeno, se para produzir manteiga, canhōes ou arados...

Enquanto um processo de discussão com a comunidade de pesquisa, englobando o estado e vários setores da sociedade, não for encarado seriamente, "soluçôes" dessa natureza, remendos numa estrutura que deveria ser corajosamente modificada para poder crescer e aumentar seu impacto, apenas poderão retardar seu desmantelamento. Se não por inanição, por perda de legitimidade perante a sociedade.

A terceira sugestão, "definir uma política de utilização de parte dos recursos dos Fundos para apoiar projetos de substituição competitiva de importações", parece estar demasiado distante da sua vocação. Em alguns deles isso parece ser impossível. Adicionalmente, será que isso não conduziria a uma situação de fazde-conta semelhante ao que ocorria nos anos 1970, quando os pesquisadores, para obterem recursos, tinham que forjar relações com as metas dos PBDCTs?

A quarta, "estabelecimento, na FINEP, de mecanismo de crédito para projetos de pesquisa de pequenas empresas, semelhante ao 'Finame Automático' desenvolvido pelo BNDES" parece desconhecer que as demandas mais urgentes das pequenas empresas, no campo para elas pouco importante da capacitação tecnológica, não são exatamente por recursos para $P \& D$. Se é que antes podia, depois dos levantamentos divulgados pelo IBGE e a CNI, ninguém medianamente informado pode hoje desconhecer isso.

Mas a sugestão supõe que há como identificar o que as pequenas empresas precisariam para se tornarem viáveis frente ao grande capital e contribuírem para o desenvolvimento do País. E, ademais, que existe capacidade no País para desenvolver a tecnologia que realmente precisam (e que o meio ambiente tolera, a força de trabalho deseja, a sociedade espera, etc.). Há que considerar a hipótese defendida por muitos de que concebê-la pode ser muito mais comple- 
xo do que o de produzir a tecnologia convencional, gerada e utilizada pelas grandes empresas ao longo de sua trajetória de exploração da fronteira tecnológica e seguindo os paradigmas dominantes da C\&T nos quais fomos formados e emulamos. E que, lamentavelmente, nossa experiência em fazê-lo nas universidades e institutos de pesquisa não é grande.

Mas essa sugestão, e mais ainda as que se seguem no Relatório, tem ínfima relação com os Fundos Setoriais.

O que leva à pergunta de por que incluí-las e, ao mesmo tempo, deixar de lado questóes centrais que deveriam entrar na agenda de discussão do GT? E, se a intenção é ampliar o escopo da reflexão, por que não começar pela discussão dos argumentos desenvolvidos pelo pensamento alternativo, de que os Fundos Setoriais não são propriamente um instrumento de política pública, mas sim um expediente ad hoc, uma não-política?

Se eles não são muito mais do que um expediente engendrado pelo governo Cardoso para captar recursos de onde se podia fazê-lo, cabe uma pergunta. Se os Fundos são um mecanismo para conferir ao mercado e suas empresas a prerrogativa de orientar em seu benefício e com critérios de curto prazo, circunstanciais, e não necessariamente coincidentes com o que parecem ser as prioridades nacionais, o nosso potencial de $\mathrm{P} \& \mathrm{D}$, por que não encarar a mudança necessária para o nosso futuro como nação soberana e justa num terreno onde nenhum "fmi" nos coloca peias?

\section{Conclusão}

Ao procurar conferir substância e conseqüência ao que acima foi caracterizado como um questionamento ao primeiro elo da Cadeia Linear de Inovação, o governo passado pretendeu favorecer a empresa nacional (e devido, quando menos, às características de nossa Constituição, também a transnacional) substituindo a derivação normativa do Modelo Institucional Ofertista Linear por uma outra orientada pela demanda empresarial, e teoricamente capaz de transformar papers em patentes.

Uma vez que, coerentemente com a visão neoliberal que lhe servia de orientação, o governo passado não tencionava alocar recursos adicionais ao complexo público do ensino superior e da pesquisa, tentou-se a todo custo quebrar 
a "espinha dorsal do corporativismo perdulário" da comunidade de pesquisa. Esta, que possui em todo o mundo grande poder na orientação da política de $\mathrm{C} \& \mathrm{~T}$, mas em países periféricos como o nosso tem um papel quase hegemônico, sendo praticamente a única responsável tanto pela formulação da política como pela execução das atividades de implementação e avaliação que dela decorrem (Dagnino \& Gomes, 2002), não se dispôs a entregar seu poder a um outro ator — a empresa privada - que considera pouco qualificado para exercê-lo.

Nessa conjuntura de progressiva politização do enfrentamento entre o governo e a comunidade científica, foram freqüentes os pronunciamentos no sentido de que um novo modelo institucional fosse concebido para alavancar uma necessária reorientação do cada vez mais disfuncional, sobretudo para o cenário do neoliberalismo então em construção, complexo de ensino superior e de pesquisa público.

O que se viu na prática, foram medidas que variaram, desde o estrangulamento do complexo público de pesquisa e ensino, até os Fundos Setoriais e a Lei da Inovação; tudo isso imerso numa prédica reiterada em torno da necessidade de fortalecer a relação U-E. Não obstante, as idéias da inexorabilidade do avanço da C\&T e de seu caráter intrinsecamente positivo, e suas conseqüências, como a auto-imposição de critérios exógenos de aferição da "qualidade" a la science citation index e a sujeição voluntária ao efeito demonstração do mainstream dos países avançados e ao seu padrão de pesquisa, foram convivendo com sinais de relevância cada vez mais fortes provenientes do ator empresa privada que passa a participar do processo decisório da PCT.

O relativo distanciamento do Modelo Ofertista Linear que ocorreu parece ser um exemplo de como, explorando o espaço de governabilidade da PCT, é possível atuar sobre causas institucionais do problema que apresenta nosso complexo de ensino superior e de pesquisa público buscando adequá-lo à mudança do contexto socioeconômico e político em curso e aos interesses de novos atores. Na mesma direção que experimentou o governo Cardoso, mas com um sentido ideologicamente contrário, parece ser possível explorar o grau de autonomia das causas institucionais em relação às causas estruturais (derivadas de nossa condição periférica) do escasso impacto de nosso complexo, com o objetivo de aproximá-lo dos interesses de atores ainda não atingidos pelos seus resultados potenciais e excluídos do processo decisório da PCT. 
De modo geral o que se tem observado foi a manutenção de um estilo de elaboração da política de pesquisa nacional, e em escala menor da PCT como um todo, que alguns chamam de laissez faire. Mas que talvez seja melhor referido através do conceito-síntese dos policy analysts, de nondecision-making. Esse estilo, por delas prescindir, tem inibido a concepção de metodologias para a decisão racional, prospectiva, transparente e participativa acerca de linhas de pesquisa, instituições, modalidades de fomento, etc. A antipatia em relação a essas metodologias, ainda que justificável nos países avançados onde a "estratégia" follow the leader é suficiente como normativa, não deveria ter contaminado nossa comunidade de pesquisa periférica. Sua virtual inexistência, ou a não aplicação das poucas que existem, talvez possa ser explicada pelo fato de que essa situação realimenta as causas institucionais que, ainda que de forma precária (e suicida), têm favorecido aquela comunidade.

É no bojo de um embate com características que na verdade transcendem a relação U-E, que o argumento HT e os arranjos como as incubadoras, parques e pólos tecnológicos que o materializam, começam a ser cada vez mais questionados. A idéia generalizada de que existiria um ganho para a atividade de pesquisa desenvolvida na universidade decorrente de uma maior interação com a empresa privada passou a ser revista. A realidade dos próprios países avançados, como a dos EUA, tomada como modelo para pautar a relação U-E em nosso País, passou a ser analisada de forma diversa. De forma coerente com o diagnóstico acima apresentado, passou a ser insistentemente questionada a efetividade dos arranjos institucionais de vinculação U-E alinhados com o argumento HT para aumentar a competitividade do País.

Passou a ser aceita a idéia de que a pesquisa universitária deve interessar as empresas não porque seus resultados sejam diretamente aplicáveis, mas sim porque ela treina os pesquisadores capazes de conceber tecnologias, em seus centros de $\mathrm{P} \& \mathrm{D}$, que as tornem competitivas. Em paralelo à crescente concordância a respeito da fragilidade dos arranjos predicados pelo argumento HT, outros consensos se foram gestando no ambiente dos envolvidos com a relação U-E, entre eles alguns que se opunham a posições assumidas pelo próprio governo. Exemplo destes é o sério questionamento que sofre a proposta de que a universidade pública brasileira empreenda sua descida da "torre de marfim" via uma maior interação com as empresas para que, dessa forma, viesse a se auto-sustentar e fortalecer. 


\section{Bibliografia}

Albornoz, M., La ciencia política ignora a la política de la ciencia. Trabalho apresentado nas Jornadas Latinoamericanas de Estudios Sociales de la Ciencia y la Tecnología. Quilmes: Argentina, 1995.

Almeida, J., "Transferência de Tecnologia e Absorção de Mão-de-obra”, Pesquisa e Planejamento Econômico, 3 (1), Brasília, 1973.

Barrella, A., O Programa de Apoio ao Desenvolvimento Científico e Tecnológico - PADCT: um exercício de análise de política. Dissertação de Mestrado. DPCT-UNICAMP, 1998.

Brito Cruz, C. A, "Universidade, a Empresa e a Pesquisa que o País precisa”, in Santos, L. et al., Ciência, Tecnologia e Sociedade: o Desafio da Interação, Londrina: IAPAR, p.191-228, 2002.

Bush, V., Science, the Endless Frontier. National Science Foundation, Washington, 1945.

Callon, M., "The Dinamics of Techno-Economic Networks”, in: Coombs, R.; Saviotti, P.; Walsh,V., Technological Change and Company Strategies: Economical and Sociological Perspectives. London: Harcourt Brace Jovanovich Publisher, 1992.

Castro, M.H.; Balán, J., A Universidade versus Setor Produtivo: a Perspectiva e a Realidade da Universidade - Caso 2: A Faculdade de Engenharia Elétrica da Unicamp e os Três Departamentos de Engenharia Elétrica da Escola Politécnica da USP. São Paulo: NUPES/ USP, ago., 52 p., 1994.

A Universidade versus Setor Produtivo: a Perspectiva e a Realidade da Universidade - Caso 3: O Instituto de Economia da Unicamp (IE) e o Departamento de Economia da FEA-USP. São Paulo: NUPES/USP, ago., 38 p., 1994.

A Universidade versus Setor Produtivo: a Perspectiva e a Realidade da Universidade - Caso 1: Os Institutos de Física Gleb Wataghin da Unicamp (IFGW) e o da USP (IF). São Paulo: NUPES/USP, jul., 41 p., 1994.

Cerantola, W. A., "O Caso do Instituto Butantan”, in Cadernos de Gestão Tecnológica. São Paulo: CYTED: NPGCT/USP, n.12, dez., 46 p., 1993.

Cox, R.N., "Lessons From 30 Years of Science Parks in the USA", in Gibb, J.M. (org.), Science Parks and Innovation Centres: Their Economic and Social Impacts. Amsterdã: Elsevier, p.17-24, 1985.

Cruz, H., Alternativas e Difusão Tecnológica: o caso do setor de calçados no Brasil. Tese de Doutorado FEA-USP, São Paulo, 1977. 
Currie, J., Science Parks in Britain — the Role for the Late 1980's. Great Britain: CSP Economic Publications, 105 p., 1985.

Dagnino, R.; Gomes, E., "O Processo Decisório na Universidade Pública Brasileira: uma visão de Análise de Política”, in Avaliação - Revista da Rede de Avaliação Institucional da Educação Superior, Campinas. v.7, fasc.4, p.43-72, 2002.

; Thomas, H., "Planejamento e Políticas Públicas de Inovação: Em direção a um marco de referência latino-americano", in Planejamento e Políticas Públicas ${ }_{2}$ Brasília, n. 23. p.205-232, 2001.

“A Relação Pesquisa-Produção: em Busca de um Enfoque Alternativo”, in Santos, L. et al., Ciência, Tecnologia e Sociedade: o Desafio da Interação, IAPAR, Londrina, p.103-146, 2002.

; Davyt, A., "Vinculacionismo/ Neovinculacionismo: racionalidades de la interacción Universidad-Empresa en América Latina (1955-1995)" in Espacios Revista Venezolana de Gestión Tecnológica, v.18, fasc.1, 49-76, 1997.

"El pensamiento en ciencia, tecnología y sociedad en latinoamérica: una interpretación política de su trayectoria”, in REDES, n.7, 1996. ; Gomes, E., "Elementos para un estado del arte de la reflexión latinoamericana en Ciencia, Tecnología y Sociedad”, in REDES, v.5, n.11, p.231-255, 1998.

Dalton, I.G., "The Objectives and Development of the Heriot-watt University Research Park", in Gibb, J.M. (ed.), Science Parks and Innovation Centres: their Economic and Social Impacts, Amsterdã: Elsevier, p.231-36, 1985.

Darós, M., O Programa Brasileiro da Qualidade e Produtividade: Uma Análise de Política. Dissertação de Mestrado. DPCT-UNICAMP, 1997.

Davis, C., Local Innovation Systems: Management and Policy Issues for Strengthening Local Capacity to Promote Technological Innovation. Science Council of Canada, 20 p., 1992.

Delapierre, M. et al., Cooperation between firms and research instituts: the french case, s.l., s.n, 41 p. (mimeo) 1988.

Díaz, R., Ofertismo em Ciência, fluxo acrítico de tecnologias forâneas e enfoque gerencial: uma problematização da política científica e tecnológica cubana. Dissertação de Mestrado. DPCTUNICAMP, 1997.

Dorfman, N.S., "Route 128: the Development of a Regional High Technology Economy”, in Research Policy, n.12, p.299-316, 1983.

Dosi, G., "Technological paradigms and technological trajectories. the determinants and directions of technological change and the transformation of the economy", in Freeman, C., Long Waves in the World Economy. London: Pinter Publishers, 1982. 
; Soete, L., "Technical change and international trade", in Dosi, G. et al. (orgs.), Technical Change and Economic Theory. Londres: Pinter Publishers, 1988.

, "The nature of the innovative process", in Dosi, G.; Soete, L. (orgs.), Technical Change and Economic Theory. Londres: Pinter Publishers, 1988.

Etzkowitz, H.; Peters, L.S., Profiting from knowledge: organizational innovations and the revolution of academics norms, s.l., s.n., 1991.

"Academic-industry relations: a sociological paradigm for economic development", in Leydersdorff, L.; Van Den Besslaar, P., Evolutionary economics and chaos theory: new directions in technology studies. London: Pinter Publishers, p.139-151, 1994.

, "Entrepeneurial science in the academy: a case of transformation of norms", in Social Problems, v.36, n.1, p.14-29, fev., 1989.

Figueiredo, N., A transferência de Tecnologia no Desenvolvimento Industrial do Brasil, Rio de Janeiro: IPEA, 1972.

FRANÇA. Ministère de l'Amenagement du territoire et des reconversions. Vingt technolopes: un premier bilan. Organizado por Thierry Bruhat. Paris: la documentation française, 214 p., 1990.

Freeman, C., "Japan: a new national system of innovation?”, in Dosi, G. et al. (eds.), Technical change na economic theory. London: Pinter Publishers, 1988.

The Economics of Industrial Innovation, 1978.

Gomes, E., "Polos tecnológicos y promoción del desarrollo. hecho o artefacto?", in Revista de estudios sociales de la ciencia, in REDES, p.177-216, n.14, v.7, nov., Buenos Aires: Universidad Nacional de Quilmes, 1999.

Grynszpan, H., "A visão Empresarial da Cooperação com a Universidade”, in Revista de Administração, v.34, p.23-31, out./dez., São Paulo, 1999.

Herrera, A., "Los determinantes sociales de la política científica en América Latina. Política científica explícita y política científica implícita", in Sabato, J. (ed.), El pensamiento latinoamericano en la problemática ciencia-tecnología-desarrollo-dependencia, Buenos Aires: Paidós. p.98$112,1975$.

Kreimer, P., “De qué objeto hablamos?”, in REDES, v.9, n.18, p. 2.225-232, 2002.

Lacave, M., Technopoles: instruments of local and regional economic development, versão inglesa de Les technopoles, outils de developpment,.s.l.: Prowse, P., 7 p.1991.

Lafite, P., "Sophia-Antipolis and its impact on the côte d' azur", in Gibb, J.M. (org.), Science Parks and Innovation Centres: their Economic and Social Impacts, Amsterdã: Elsevier, p.87-90,1985. 
Lundvall, B. (org.), National systems of innovation: towards a theory of innovation and interactive learning. Londres: Pinter Publishers, 1992.

, "Innovation as an interactive process: from user-producer interaction to the national system of innovation", in Dosi, G.; Soete, L. (orgs.), Technical Change and Economic Theory. Londres: Pinter Publishers, 1988.

Product innovation and user-producer interaction. Aalborg: Aalborg University Press, 1985.

Marcovitch, J. A, "Cooperação da universidade moderna com o setor empresarial”, in Revista de Administração, v.34, p.13-17, out./dez., São Paulo,1999.

Medeiros, J.A., As novas tecnologias e a formação dos pólos tecnológicos brasileiros, in Estudos Avançados. Coleção Documentos. Série Política Científica e Tecnológica, 5, 31p. São Paulo: IEA/USP, 1990.

MITI. Industrial Location and Environmental Protection Bureau. Outline and present status of the Technopolis project, s.l.: MITI, 16 p., 1990. (mimeo)

Montalvo, L., A politica cientifica e tecnológica em Cuba: avaliação e elementos para seu aperfeiçoamento, tese de doutorado, DPCT - UNICAMP, 1998.

National Science Foundation. Science and Engineering Indicators, 1996. Washington, DC: National Science Board, National Science Foundation, 1997.

Nelson, R. (org.), National Innovation System: a Comparative Analysis. New York: Oxford University Press, 1993.

Niosi, J. et al., "National systems of innovation: in search of a workable concept", in Technology in Society, v.15, n.2, 1993.

PCI (Programa de Competitividade Industrial). Politica industrial e de comércio exterior (PICE), 2a..ed. rev., Brasília, set., 51 p., 1991.

PICE (Política Industrial e de Comércio Exterior), Diretrizes gerais, 3ํe․, Brasília, out., 19 p., 1992.

Plonski, G.A. (org.), Cooperacion empresa-universidad en Iberoamérica: avances recientes, São Paulo: CYTED, 114 p., 1995.

, "Beyond Triads: An Institutional Approach to Knowledge-Based Economic Development", in Anais da University and the Global Knowledge Economy: A Triple Helix of University-Industry-Government Relations, Amsterdā, 3-6 jan., 1996.

"Novas alianças e parcerias em ciência, tecnologia e engenharia: a cooperação universidade-indústria”, in Anais do XV Simpósio Nacional de Pesquisa em Administração em Ciência e Tecnologia. São Paulo, 9 p., 1990. 
Porter, M., The Competitive Advantage of Nations, Nova York: Free Press, 1990.

Quirino, T.R.O., "Programa de soja na Universidade Federal de Viçosa”, Cadernos de Gestão Tecnológica, São Paulo: CYTED: NPGCT/USP n.17, dez., 1993.

Roberts, E.B.; Wainer, H.A., "New enterprises on the Route 128”, in Science Journa, p. 78-83, dez., 1968.

Rosenberg, N., Inside the black box — technology and economics, New York: Cambridge University Press, 1982.

Sabato, J. (ed.), El pensamiento latinoamericano en la problemática ciencia-tecnología-desarrollodependencia, Buenos Aires: Paidós, 1975.

"El origen de algunas de mis ideas", in Repensando la Política Tecnológica - Homenaje a Jorge Sabato, Buenos Aires: Ediciones Nueva Visión. p.103-114, 1994.

; Mackenzie, M., La producción de tecnología-autónoma o transnacional, México, ILET - Nueva Imagen, 1982.

Sagasti, F., Science and technology for development: main comparative report of the science and technology policy instruments project (STPI), Otawa: IDRC, 1978.

Saxenian, A.L., "The origins and dynamics of production networks in Silicon Valley”, in Research Policy, n.20, p.423-37, 1991.

Segatto, A. P., Análise do Processo de Cooperação Tecnológica Universidade-Empresa: um estudo exploratório, 98 p., São Paulo: USP, 1996.

Shattock, M.L., "Investiment factors in Britain science park development”, in Gibb, J.M. (ed.), Science parks and innovation centres: their economic and social impacts, Amsterdã: Elsevier, p.142-48, 1985.

Stal, E., "Metal Leve S. A. Indústria e Comércio", in Cadernos de Gestão Tecnológica, São Paulo: CYTED: NPGCT/USP n.11, dez., 27 p., 1993.

Stefanutto, G. A, Induistria de Software no Brasil - 2002. Fortalecendo a Economia do Conhecimento, Softex, Campinas, 2003.

Sutz, J., "Comentarios a las reflexiones de Terry Shinn”, in REDES, v.9, n.18, p.213-224, 2002.

Takayanagui, A. D., "La Universidad Innovadora - una estrategia para el cambio de las Universidades mexicanas en los 90's”, Cadernos de Gestão Tecnológica, USP, n.1, 24, 31 p., São Paulo: CYTED: NPGCT/,1995. 
Tesse, P. Y., “One 'technopole' - A Network Innovation of Centres: the Lyon Model”, in Gibb, J.M. (org.), Science Parks and Innovation Centres: their Economic and Social Impacts, Amsterdã: Elsevier, 1985.

Thomas, H., Dinâmicas de inovação na Argentina (1970-1995) Abertura comercial, crise sistêmica e rearticulação, Tese de Doutorado, São Paulo: DPCT, UNICAMP, 1999.

Torkomian, A., Estrutura de pólos tecnológicos: um estudo de caso, 193 p. Dissertação (Mestrado em Administração de Empresas) Faculdade de Economia, Administração e Contabilidade: Universidade de São Paulo, São Paulo: USP, 1992.

UNESCO. World Science Report 1995, Paris, 1996.

Varsavsky, O., Ciencia politica y cientificismo, Buenos Aires: Centro Editor de America Latina, 1969.

Webster, A.J.; Etzkowitz, H., Academic-industry relations: the second academic revolution?, 31 p., London: Science Policy Support Group, 1991. (SPSG concept paper n.12).

Weiss, J. M. G., “Centros de Excelência em P\&D na empresa privada: o caso da Rhodia S. A.”, in Cadernos de Gestão Tecnológica, n.16, dez., São Paulo: CYTED: NPGCT/USP, 1993. 